\title{
Predictors of Adolescent Parent Communication and Safe Sexual Behaviour among In-School Adolescents
}

\author{
Funmito O. Fehintola ${ }^{1}$, Akintunde O Fehintola ${ }^{2}$, Taiwo A. Olowolaju ${ }^{1}$, Idowu O. Oluwagbamila ${ }^{1}$, \\ Ayobode A. Omidiji ${ }^{1}$, Caleb A. Adegbenro ${ }^{1}$ \& Olapeju A. Esimai ${ }^{1}$ \\ ${ }^{1}$ Department of Community Health, College of Health Sciences, Obafemi Awolowo University, Ile-Ife, Nigeria \\ ${ }^{2}$ Obstetrics, Gynaecology, and Perinatology Department, Obafemi Awolowo University, Ile-Ife, Nigeria \\ Correspondence: Funmito O. Fehintola, Department of Community Health, College of Health Sciences, Obafemi \\ Awolowo University, Ile-Ife, Osun State, Nigeria. Tel: 234-803-391-3964.
}

Received: December 16, 2020 Accepted: March 21, 2021 Online Published: April 13, 2021

doi:10.5539/gjhs.v13n5p53 URL: https://doi.org/10.5539/gjhs.v13n5p53

\begin{abstract}
Adolescents in communicating about their sexual and reproductive health (SRH) issues are faced with the obstacles created by expected social norms and taboos related to sexuality and gender. This study aims to determine the relationship between adolescent-parent communication and its relationship with safe sex behaviour among adolescents.

The study was a descriptive cross-sectional. Data was collected from 400 adolescents in Ife-East local government using a pre-tested semi-structured questionnaire. We used a multistage sampling technique to select the required study subjects. We carried out simple frequencies and chi-square.

Fifty -five percent $(55.3 \%)$ of the respondents were females, while $44.8 \%$ are males. The mean age $( \pm \mathrm{SD})$ of the participants was $15.50 \pm 1.55$ years. Of the respondents, only $37 \%$ had good knowledge of sexual and reproductive health issues, while $63 \%$ had poor knowledge of sexual and reproductive health issues. The predictors of adolescent parent communication among respondents are private schools $(\mathrm{OR}=2.546, \mathrm{P}=0.005, \mathrm{CI}=1.327-4.885)$, Female sex $(\mathrm{OR}=12.128, \mathrm{P}<0.001, \mathrm{CI}=11.590-25.534)$, family size $(\mathrm{OR}=14.772, \mathrm{P}=0.003, \mathrm{CI}=13.037-20.015)$ and good knowledge of sexual and reproductive health issues $(\mathrm{OR}=19.521, \mathrm{P}=0.007, \mathrm{CI}=19.521-29.078)$. There is a statistically significant relationship between adolescent parent communication and safe sexual behaviour $\left(\mathrm{X}^{2}=152.998, \mathrm{P}<0.001, \mathrm{df}=1\right)$.

The findings of our study revealed that adolescents were not communicating much with parents about sexual and reproductive health issues; and that there is an association between adolescent parent communication and safe sexual behaviour.
\end{abstract}

Keywords: adolescents, parents, communication, sexual and reproductive health, safe sex behaviour

\section{Introduction}

There are more than one billion adolescents all over the world. About $70 \%$ of them live in resource-poor countries (Department of Economic and Social Affairs (DESA, 2010). Studies have shown that adolescents have a limited understanding of various physiological changes that take place in them (Farzaneh, Lori, \& Karima, 2008; Jejeebhoy, 2006; Seme \& Wirtu, 2008). This lack of knowledge about pubertal changes may harm this group of people. In the past, researchers noticed that many adolescents who survived all childhood health challenges enjoyed a period of relatively low morbidity and mortality. However, due to civilization, urbanization, and lifestyle changes, adolescents' health is presently at stake (Berhane, Berhane, \& Fantahun, 2005; Shiferaw, Getahun, \& Asres, 2014). The greatest threat to adolescents' wellbeing is sexually transmitted infections and other reproductive health challenges (Berhane et al., 2005).

Across the globe, between 2.5 and 3 million adolescents acquire sexually transmitted infections (STIs) annually (Fanta, Lemma, Sagaro, \& Meskele, 2016). This fact implies that in the developed countries, approximately one out of every ten adolescents acquire STIs annually. More than one million pregnancies occur among adolescents each year, out of which sixty percent are unwanted due to unprotected sexual intercourse (Yesus \& Fantahun, 2010). 
Sixteen million girls aged 15-19 give birth annually. This proportion is about $11 \%$ of all deliveries globally (Morris \& Rushwan, 2015); 95\% of these deliveries occur in developing countries (Morris \& Rushwan, 2015). Significant differences arise across regions; for example, the proportion of births from teenage pregnancy to all deliveries range between approximately $2 \%$ in China to $18 \%$ in Latin America and the Caribbean, to more than $50 \%$ in Sub-Saharan Africa (WHO(Organization, 2004). Teenage pregnancy is a significant problem. In low-middle income countries (LMICs), about ten percent of teenagers become mothers before 16, with the highest rates in Sub-Saharan Africa and Southeast Asia (WHO (Organization, 2004).

In communicating about sexual and reproductive health (SRH) issues, adolescents tend to face obstacles created by expected societal norms and beliefs regarding sexuality and gender (Kusheta, Bancha, Habtu, Helamo, \& Yohannes, 2019; Motsomi, Makanjee, Basera, \& Nyasulu, 2016). These obstacles lead to a culture of silence, especially for the girls, in expressing their worries, discussing, and accessing information about SRH (Motsomi et al., 2016). Similarly, because of religious and cultural beliefs, parents tend to avoid discussion about sexual issues with adolescents. Parents believe they are too young for such discussion. This belief, in turn, hinders adolescent-parent communication on sexual health issues by creating an unfavorable environment for discussion (Kusheta et al., 2019; Motsomi et al., 2016).

Adolescents need their parents to spend time with them and show a genuine interest in them. Although adolescents often find it difficult to discuss sexuality with their parents, they tend to imbibe healthy sexual behavior when their parents engage in a robust discussion on SRH issues (DeVore \& Ginsburg, 2005). Researches have also shown positive parenting practices involve discussion on sex-related topics, such as abstinence, contraception, and combatting HIV and other sexually transmitted infections (STIs) (DeVore \& Ginsburg, 2005; Guilamo-Ramos \& Bouris, 2008).

In Nigeria, surveys have not adequately explored the predictors of Adolescent-parent communication on sexual and reproductive health (SRH) challenges. Titiloye and colleagues employed mixed methods to estimate SRH discussion between adolescents and their parents. This method is limited in depth of information about triggers of parent-child communication and does not look into the predictors of adolescent-parent communication SRH issues (Titiloye \& Ajuwon, 2017). Izugbara used qualitative methods to explore how and why these discussions happen. He conducted the study in rural areas alone, limiting its transferability to non-rural settings (Izugbara, 2008). These studies were selective in scope, coverage, and assessment of adolescents' SRH issues. This present study conducted more comprehensive research on adolescent-parent communication predictors on SRH issues and its association with adopting safe sex behaviors.

\section{Methodology}

We carried it out in Ife East local government (LGA) of Osun State, Nigeria, between August and October 2019. Geographically, Ile-Ife lies on latitude $7^{\circ} 28^{\prime} \mathrm{N}$ and $7^{\circ} 45^{\prime} \mathrm{N}$ and longitude $4^{\circ} 30^{\prime} \mathrm{E}$ and $4^{\circ} 34^{\prime} \mathrm{E}$. The city experiences two distinct seasons, the rainy season spanning between April and October and the dry season between November and March. The average rainfall is about $1,000-1,250 \mathrm{~mm}$, with the highest temperature hovering over $28.3^{\circ}$ Ife East LGA lies between latitude 7020 "N and longitude 4033 "E. We classified urban settlement with a total population of about 221,340, a mixture of Yoruba, Igbo, Hausa, and other tribes (Commission, 2009). The Local Government Area has 84 senior secondary schools.

\subsection{Study Design}

The study employed a descriptive cross-sectional design.

\subsection{Target and Study Population}

The study population is adolescents (10-19years) in selected schools.

\subsection{Sample Size}

We determined the sample size with the formula for estimating single proportions described by Armitage \& Berry and cited in Gahlinger \& Abramson). P is assumed prevalence of $87 \%$ (Fanta et al., 2016). Considering 10\% non-response rate

$\mathrm{n}=350+35=385$. We rounded this number up to 400 for robust sampling.

\subsection{Sampling Technique}

We selected the respondents using the multi-stage sampling technique. The researcher obtained a list of all secondary schools in the study area, which had already been classified as public and private schools from the Ife East Local inspector of Education office. Stage 1: Six public and private senior secondary schools were selected by 
balloting from 84 senior secondary schools within the LGA. We evenly distribute the sample size over the six schools chosen to know the number of respondents per school, giving a total number of 67 respondents per school. Stage 2: Schools selected had more than an arm, from which we selected two arms of each class using a simple random sampling technique by balloting. Stage 3: Eligible respondents from the arms chosen were selected from the class register using simple random sampling.

\subsection{Inclusion and Exclusion Criteria}

Inclusion criteria are Students that are in session during data administration. Students who are seriously sick at the time of data collection were excluded from the study. Students writing their senior secondary school certificate examination. Single-Sex Secondary School.

\subsection{Data Collection Methods}

The adolescent-parent questionnaire was adopted from previous studies for data collection. The question has three sections: A. Socio-demographic status, B. Knowledge on major selected aspects of SRH, C. Level of communication on SRH, and Safe sexual behavior questionnaire. We developed the safe sexual behavior scale according to Dilorio et al. (DiIorio, Parsons, Lehr, Adame, \& Carlone, 1992). It contains 27 items, which responses never have, sometimes, almost all the times, and always. We scored the items by awarding 1 for never and 4 for always, giving a score range of 27-108. A score of 78 and below indicates a lower level of safer sex behavior and scores greater than 78 indicate a higher level of safer sex behavior. The questionnaire was pre-tested among secondary school adolescents in Ife Central Local Government Area to ensure its reliability and content validity, and we made necessary changes after that.

\subsection{Data Analysis}

Each questionnaire was cross-checked daily on the field to ensure accurate data collection before data entry. The statistician analyzed the data using Statistical Package for the Social Sciences (SPSS) soft wear package version 20.0 .

We generated frequencies and percentages for socio-demographic factors, including mean (standard deviation) for the age. The statistician generated statistical indices (chi-square, p-value, and degree of freedom) for the association between socio-demographic factors and adolescent-parent communication on SRH.

He also generated statistical indices for a statistical association between adolescent-parent communication on SRH and safe sexual behavior. We presented the data using tables. We used the Chi-square test to compare categorical variables and set statistical significance at $\mathrm{p}<0.05$.

We generated Multivariate analysis using binary logistic regression for statistically significant socio-demographic factors and safe sexual behaviors.

\subsection{Ethical Consideration}

We sought ethical approval from the institute's ethical and research committee of public health OAU, Ile-Ife. We gave all participants verbal and written information about the study and the right to withdraw at any time without suffering any form of disadvantage. We then obtained their verbal consent. The researcher also assured them of confidentiality of their identities and information.

\section{Results}

Table 1 reveal s that fifty-five percent (55.3\%) of the respondents were females, while $44.8 \%$ are males. The respondents' mean age was $15.50 \pm 1.55$ years. Also, half of the students $(52.5 \%)$ were in SS 1 . Most of the respondents $(90.3 \%)$ belonged to the Yoruba ethnic group, and the majority of them $(87.8 \%)$ were Christians by religion. Seventy -six percent (77.5\%) of the respondents were living with both parents. Less than half (46.5\%) of their parents were living together. The respondents' mean family size was $4.74 \pm 1.56$. Forty percent $(40.0 \%)$ of the respondents' mothers were secondary school certificate holders, and $23.8 \%$ of respondents' mothers were small-scale merchant and private employees each. Thirty-three $(33.0 \%)$ of the respondents' fathers were postgraduate degree holders, and $39.0 \%$ of respondents' fathers were government employees. 
Table 1. Socio-Demographic Characteristics of respondents

\begin{tabular}{|c|c|}
\hline Variables & Frequency n (\%) \\
\hline \multicolumn{2}{|l|}{ Age(years) } \\
\hline $10-13$ & $49(12.3 \%)$ \\
\hline $14-16$ & $219(54.8 \%)$ \\
\hline $17-19$ & $132(33.0 \%)$ \\
\hline Total & $400(100 \%)$ \\
\hline Mean & 15.50 \\
\hline Standard Deviation & 1.55 \\
\hline \multicolumn{2}{|l|}{ School } \\
\hline Private & $183(45.8 \%)$ \\
\hline Government & $217(54.3 \%)$ \\
\hline Total & $400(100 \%)$ \\
\hline \multicolumn{2}{|l|}{ Class } \\
\hline SS 1 & $210(52.5 \%)$ \\
\hline $\mathrm{SS} 2$ & $190(47.5 \%)$ \\
\hline Total & $400(100 \%)$ \\
\hline \multicolumn{2}{|l|}{ Gender } \\
\hline Male & $179(44.8 \%)$ \\
\hline Female & $221(55.3 \%)$ \\
\hline Total & $400(100 \%)$ \\
\hline \multicolumn{2}{|l|}{ Religion } \\
\hline Christianity & $351(87.8 \%)$ \\
\hline Muslim & $46(11.5 \%)$ \\
\hline Others & $3(0.8 \%)$ \\
\hline Total & $400(100 \%)$ \\
\hline \multicolumn{2}{|l|}{ Ethnicity } \\
\hline Yoruba & $361(90.3 \%)$ \\
\hline Hausa & $3(0.8 \%)$ \\
\hline Ibo & $27(6.8 \%)$ \\
\hline Others & $9(2.3 \%)$ \\
\hline Total & $400(100 \%)$ \\
\hline \multicolumn{2}{|l|}{ Parents Marital status } \\
\hline Together & $186(46.5 \%)$ \\
\hline Separated & $146(36.5 \%)$ \\
\hline Divorced & $34(8.5 \%)$ \\
\hline Widowed & $34(8.5 \%)$ \\
\hline Total & $400(100 \%)$ \\
\hline \multicolumn{2}{|l|}{ Family Size } \\
\hline $1-4$ & $86(21.5 \%)$ \\
\hline$>/=5$ & $314(78.5 \%)$ \\
\hline Total & $400(100 \%)$ \\
\hline
\end{tabular}




\begin{tabular}{lc}
\hline Mean & 4.74 \\
Standard Deviation & 1.56 \\
\hline
\end{tabular}

Mother's educational status

Non-formal

$17(4.3 \%)$

Primary school certificate

$44(11.0 \%)$

Secondary school certificate

$160(40.0 \%)$

Diploma

$25(6.3 \%)$

Tertiary education

$52(13.0 \%)$

Postgraduate

$102(25.5 \%)$

Total

$400(100 \%)$

Father's educational status

Non-formal

$16(4.0 \%)$

Primary school certificate

$42(10.5 \%)$

Secondary school certificate

$121(30.3 \%)$

Diploma

$35(8.8 \%)$

Tertiary education

$54(13.5 \%)$

Post-graduate

$132(33.0 \%)$

Total

$400(100 \%)$

Mother's occupation

House wife

$42(10.5 \%)$

Employed(private)

$95(23.8 \%)$

Employed (Government)

$82(20.5 \%)$

Small scale merchant

$95(23.8 \%)$

Farmer

$23(5.8 \%)$

Others

$63(15.8 \%)$

Total

$400(100 \%)$

Father's occupation

Employed(private)

$89(22.3 \%)$

Employed (Government)

$156(39.0 \%)$

Small scale merchant

$37(9.3 \%)$

Farmer

$55(13.8 \%)$

Others

$63(15.8 \%)$

Total

$400(100 \%)$

Table 2 shows the knowledge assessment of major selected SRH issues among the participants. A total of 320 $(80 \%)$ participants knew about the age at first menses (menarche). The reported age at menarche in this study was $11.01 \pm 1.98$ years. Only $37 \%$ of the participants had good knowledge of SRH issues, while $63 \%$ had poor knowledge. 
Table 2. Knowledge of major selected sexual and reproductive health issues among respondent

\begin{tabular}{|c|c|}
\hline Variables & Frequency (\%) \\
\hline \multicolumn{2}{|c|}{ At what age does menstruation starts? } \\
\hline $9-13$ & $280(70.0 \%)$ \\
\hline $14-18$ & $40(10.0 \%)$ \\
\hline $19-24$ & $80(100 \%)$ \\
\hline \multicolumn{2}{|l|}{ Do you know STDs? } \\
\hline Yes & $279(69.8 \%)$ \\
\hline No & $121(30.3 \%)$ \\
\hline \multicolumn{2}{|l|}{ *Which STD do you know? } \\
\hline Chancroid & $108(49.1 \%)$ \\
\hline Syphilis & $110(55.0 \%)$ \\
\hline Gonorrhea & $200(90.1 \%)$ \\
\hline Lymphogranuloma venerum & $43(19.5 \%)$ \\
\hline HIV/AIDS & $215(97.7 \%)$ \\
\hline Herpes simplex & $23(10.4 \%)$ \\
\hline \multicolumn{2}{|c|}{ Do you know about contraceptives } \\
\hline Yes & $228(57 \%)$ \\
\hline No & $172(43 \%)$ \\
\hline \multicolumn{2}{|c|}{ *Which contraceptives do you know? } \\
\hline Pill & $175(79.5 \%)$ \\
\hline Depo-Provera & $54(24.5 \%)$ \\
\hline Implant & $182(82.7 \%)$ \\
\hline IUCD & $89(40.4 \%)$ \\
\hline Condoms & $218(99.1 \%)$ \\
\hline \multicolumn{2}{|l|}{ Knowledge score } \\
\hline Good: (mean score $\geq 5.5$ ) & $148(37 \%)$ \\
\hline Poor: (mean score < 5.5 ) & $252(63 \%)$ \\
\hline
\end{tabular}

Table 3 shows that two-thirds (63.7\%) of the respondents have discussed SRH issues, out of which $39.2 \%$ had talked with their parents while $56.9 \%$ and $3.9 \%$ have consulted with their peers and siblings, respectively.

Table 3. Adolescent communication on SRH issues

\begin{tabular}{lcc}
\hline Have you ever had communication on & Frequency & Percentage \\
SRH issues in the past? & 255 & $(63.7 \%)$ \\
\hline Yes & 145 & $(36.3 \%)$ \\
No & & $(39.2 \%)$ \\
\hline To whom do you discuss? & 100 & $(56.9 \%)$ \\
Parents & 145 & $(3.9 \%)$ \\
Peer friend & 10 & $60.0 \%$ \\
Others & & $40.0 \%$ \\
\hline Adolescent -parent communication & 60 & $100.0 \%$ \\
Sexually active & 40 & \\
Not sexually active & 100 & \\
Total & & \\
\hline
\end{tabular}


Table 4 Three percent of the respondents insist on condom use, while 3.34\% stop foreplay early enough to put on a condom (or for my partner to put on a condom) during sexual intercourse. Fifteen percent of the respondents engage in sexual intercourse on a first date, while 1.0\% abstain from sexual intercourse when they do not know the partner's sexual history. Seventeen percent (17\%) of the sexually active respondents practice safe sexual behavior, while $83.3 \%$ do not practice safe sexual behavior.

Table 4. Participation in Safe sexual behavior questionnaire among respondents

\begin{tabular}{|c|c|c|}
\hline Behavior & Frequency(299) & Percentage $(\%)$ \\
\hline * I push for condom use when I have sexual intercourse & 9 & $3.01 \%$ \\
\hline $\begin{array}{l}\text { * I use cocaine or other drugs before or during sexual } \\
\text { intercourse. }\end{array}$ & 55 & $18.39 \%$ \\
\hline $\begin{array}{l}\text { * I stop foreplay early enough to put on a condom (or for } \\
\text { my partner to put on a condom). }\end{array}$ & 10 & $3.34 \%$ \\
\hline $\begin{array}{l}\text { * I enquire from potential sexual partners about their } \\
\text { sexual histories. }\end{array}$ & 12 & $4.01 \%$ \\
\hline $\begin{array}{l}\text { * I avoid direct contact with my partner's semen or vaginal } \\
\text { secretions. }\end{array}$ & 10 & $3.34 \%$ \\
\hline $\begin{array}{l}\text { * My partner and I use spermicide and a condom with each } \\
\text { act of sexual intercourse. }\end{array}$ & 11 & $3.68 \%$ \\
\hline $\begin{array}{l}\text { * I have sexual intercourse with intravenous drugs (IV } \\
\text { drugs) users. }\end{array}$ & 8 & $2.67 \%$ \\
\hline $\begin{array}{l}\text { *I ask my potential sexual partners about the history of } \\
\text { bisexual/homosexual practices. }\end{array}$ & 7 & $2.34 \%$ \\
\hline * I engage in sexual intercourse on a first date. & 45 & $15.1 \%$ \\
\hline $\begin{array}{l}\text { * I abstain from sexual intercourse when I do not know my } \\
\text { partner's sexual history. }\end{array}$ & 4 & $1.34 \%$ \\
\hline $\begin{array}{l}\text { * I avoid sexual intercourse when I have sores or irritation } \\
\text { in my genital area. }\end{array}$ & 4 & $1.34 \%$ \\
\hline $\begin{array}{l}\text { * If I know an encounter may lead to sexual intercourse, I } \\
\text { carry a condom with me. }\end{array}$ & 5 & $18.39 \%$ \\
\hline $\begin{array}{l}\text { * I insist on examining my sexual partner for sores, cuts, or } \\
\text { abrasions in the genital area. }\end{array}$ & 2 & $0.7 \%$ \\
\hline $\begin{array}{l}\text { * If I disagree with my partner's information on safer sex } \\
\text { practices, I state my perspective. }\end{array}$ & 11 & $3.68 \%$ \\
\hline $\begin{array}{l}\text { * I engage in oral sex without using protective barriers } \\
\text { such as a condom or rubber dam. }\end{array}$ & 54 & $18.1 \%$ \\
\hline $\begin{array}{l}\text { * I use rubber gloves for sexual foreplay when I have cuts } \\
\text { or abrasions on my hands. }\end{array}$ & 10 & $3.34 \%$ \\
\hline $\begin{array}{l}\text { If swept away in the moment's passion, I have sexual } \\
\text { intercourse without using a condom. }\end{array}$ & 50 & $16.7 \%$ \\
\hline * I engage in anal intercourse. & 33 & $11.0 \%$ \\
\hline $\begin{array}{l}\text { * I ask my potential sexual partners about the history of IV } \\
\text { drug use. }\end{array}$ & 12 & $4.01 \%$ \\
\hline $\begin{array}{l}\text { If I know an encounter may lead to sexual intercourse, I } \\
\text { have a mental plan to practice safer sex. }\end{array}$ & 4 & $1.34 \%$ \\
\hline $\begin{array}{l}\text { * If my partner insists on sexual intercourse without a } \\
\text { condom, I refuse to have sexual intercourse. }\end{array}$ & 12 & $4.01 \%$ \\
\hline
\end{tabular}




\begin{tabular}{lcc}
\hline$*$ I avoid direct contact with my sexual partner's blood. & 14 & $4.68 \%$ \\
\hline$*$ It is difficult for me to discuss sexual issues with my & 55 & $18.39 \%$ \\
sexual partners & 9 & $3.01 \%$ \\
\hline $\begin{array}{l}* \text { I initiate the topic of safer sex with my potential sexual } \\
\text { partner. }\end{array}$ & 32 & $10.7 \%$ \\
\hline$*$ I engage in anal intercourse without using a condom. & 32 & $10.7 \%$ \\
\hline$*$ 1 drink alcoholic beverages before or during sexual & & 16.75 \\
\hline intercourse. & 50 & $83.3 \%$ \\
\hline Safe Sexual behavior & 249 & \\
\hline Unsafe Sexual behavior & & \\
\hline$*$ Multiple responses & & \\
\hline
\end{tabular}

*Multiple responses.

Table 5 shows a statistically significant relationship between adolescent parent communication and safe sexual behavior $\left(\mathrm{X}^{2}=152.998, \mathrm{P}<0.001, \mathrm{df}=1\right)$.

Table 5. Relationship between AdolescentAdolescent - parent communication and safe sexual behavior

\begin{tabular}{lccc}
\hline A-P Communication & \multicolumn{2}{c}{ Safe sexual behavior (\%) } & Unsafe sexual behavior \\
$(50)$ & $(249)$ & $18(7.2)$ & Statistical indices \\
\hline Yes (60) & $42(84.0)$ & $231(92.8)$ & $\mathrm{X}<0.001$ \\
\hline No (239) & $8(16.0)$ & $\mathrm{Df}=1$ \\
\hline
\end{tabular}

Table 6 reveals the predictors of adolescent parent communication among respondents. Respondents in private schools were three times more likely to discuss sexual and reproductive health issues with their parents than their public school counterparts $(\mathrm{OR}=2.546, \mathrm{P}=0.005, \mathrm{CI}=1.327-4.885)$. Female respondents are 12 times more likely to discuss sexual and reproductive health issues with their parents than males $(\mathrm{OR}=12.128, \mathrm{P}<0.001, \mathrm{CI}=11.590-$ 25.534). Respondents with family size 1-4 were 15 times likely to discuss sexual and reproductive health issues with their parents compared with their counterparts from family size $\geq 5(\mathrm{OR}=14.772, \mathrm{P}=0.003, \mathrm{CI}=13.037$ -20.015 ). Respondents with good knowledge were 19 times more likely to discuss sexual and reproductive health issues with their parents than their counterparts with poor knowledge $(\mathrm{OR}=19.521, \mathrm{P}=0.007, \mathrm{CI}=19.521-29.078)$.

Table 6. Predictors of Adolescent Parent Communication Among Respondents

\begin{tabular}{|c|c|c|c|c|}
\hline \multirow{2}{*}{ Variable } & \multirow{2}{*}{ Odds Ratio } & \multicolumn{2}{|c|}{ (95\% Conf. Interval) } & \multirow{2}{*}{ P-value } \\
\hline & & Lower limit & Upper limit & \\
\hline \multicolumn{5}{|l|}{ School } \\
\hline Public (RC) & 1.0000 & & & \\
\hline Private & 2.546 & 1.327 & 4.885 & $0.005^{*}$ \\
\hline \multicolumn{5}{|l|}{ Sex } \\
\hline Male (RC) & 1.0000 & & & \\
\hline Female & 12.128 & 11.590 & 25.534 & $0.000^{*}$ \\
\hline \multicolumn{5}{|l|}{ Family size } \\
\hline$\geq 5(\mathrm{RC})$ & 1.0000 & & & \\
\hline $1-4$ & 14.772 & 13.037 & 20.015 & $0.003 *$ \\
\hline
\end{tabular}




\section{Knowledge of sexual and \\ reproductive health issues}

Poor (RC)

1.0000

Good
19.521
12.253

29.078

$0.007 *$

\section{Discussion}

Adolescent sexuality is a significant point of discussion at different health fora over the past decade. Previous studies established the fact that Adolescent- parent communication is central to safe sexual practice among adolescents.

About one-third (39.2\%) of the adolescents that ever communicated on SRH issues discussed with their parents, while $56.9 \%$ discussed it with their friends. This result is higher than those of the studies from Bullen Ethiopia, Awabel, and Lesotho, which place the prevalence of Adolescent -parent communication on SRH issues at (29\%), (25.3\%), (20\%), respectively(Ayehu, Kassaw, \& Hailu, 2016; Mturi, 2003; Yesus \& Fantahun, 2010). This present study's findings are lower than the research conducted in Zimbabwe (44\%) (Kim, Kols, Nyakauru, Marangwanda, \& Chibatamoto, 2001). Cultural differences associated with discussing sensitive matters such as SRH issues may account for this variation.

We also found a statistically significant association between adolescent-parent communication and safe sexual behavior. This study revealed that $84.0 \%$ of adolescents who practice safe sexual behavior discussed SRH issues with their parents. In contrast, $92.8 \%$ of those who didn't practice safe sexual behavior had no prior communication with their parents. This finding is similar to the results of previous studies. They showed that communication with parents plays a major role in enhancing safe sexual behavior (DeVore \& Ginsburg, 2005; Guilamo-Ramos \& Bouris, 2008; Guilamo-Ramos et al., 2012; Widman, Choukas-Bradley, Noar, Nesi, \& Garrett, 2016).

Few of the respondents in this study insist on condom use, stop foreplay long enough to put on a condom, and abstain from sexual intercourse when they do not know the partner's sexual history. This result is less than $34.8 \%$ reported from Bale, South West Ethiopia (Dida, Kassa, Sirak, Zerga, \& Dessalegn, 2014), 47.9\% from Woreta Town, Northwest Ethiopia (Birhanu, Bisetegn, \& Woldeyohannes, 2014), and Harar, East Ethiopia (Yadeta, Bedane, \& Tura, 2014). Cultural differences and changes in associated interventions concerning sexual and reproductive health problems among the study settings may account for this variation.

The predictors of adolescent-parent communication in this study include small family size and good knowledge of sexual and reproductive health issues. Our survey revealed that there is an association between sex and adolescent parent communication. This result is comparable to previous reports, which showed that female sex is a predictor of adolescent-parent communication SRH. This finding might be because girls tend to spend more time at home with their parents; and that parents usually focus more on the girls regarding abstinence and pregnancy avoidance (Ayehu et al., 2016; Kumi-Kyereme, Awusabo-Asare, Biddlecom, \& Tanle, 2007; Motsomi et al., 2016).

This study showed that good knowledge of SRH issues is a predictor of adolescent parent communication. This finding is similar to previous survey reports, which showed that knowing sexual and reproductive health issues(SRH) is a strong predictor of adolescent parent communication on SRH issues (Fanta et al., 2016; Melaku, Berhane, Kinsman, \& Reda, 2014). This finding may be because students who know SRH issues were eager to initiate a discussion with their parents on SRH issues.

\section{Conclusion}

This study revealed that the prevalence of adolescent-parent communication is low in our setting even though it plays a central role in enhancing safe sexual behavior in adolescents. The study also identified good knowledge of $\mathrm{SRH}$ issues as a predictor of adolescent-parent communication on sexuality.

\subsection{Recommendation}

Parents should engage both male and female adolescents equally during the discussion on Reproductive Health issues. Responsible agencies like the district health office, town administrative office, and others should provide parents with the necessary information, education, communication material, and communication skills on Reproductive Health-related issues. There should be transparency at home and in the community to enhance open discussion among family members, especially adolescents. We should furnish adolescents with accurate RH 
information in various ways, such as participating in different health clubs both in and outside school. Policymakers should introduce comprehensive family life education programs into the school curriculum. Advocacy should target homes, churches, mosques, and health facilities regarding adolescent-friendly SRH services.

\subsection{Limitation of the Study}

We base Adolescent-parent communication on sexual and reproductive health issues on self-report from the adolescents, and the study did not explore factors from the parent's perspective.

\section{Competing Interests Statement}

The authors declare that there are no competing or potential conflicts of interest.

\section{References}

Ayehu, A., Kassaw, T., \& Hailu, G. (2016). Young people's parental discussion about sexual and reproductive health issues and its associated factors in Awabel woreda, Northwest Ethiopia. Reproductive health, 13(1), 19. https://doi.org/10.1186/s12978-016-0143-y

Berhane, F., Berhane, Y., \& Fantahun, M. (2005). Adolescents' health service utilization pattern and preferences: Consultation for reproductive health problems and mental stress are less likely. Ethiopian Journal of Health Development, 19(1), 29-36. https://doi.org/10.4314/ejhd.v19i1.9968

Birhanu, A. M., Bisetegn, T. A., \& Woldeyohannes, S. M. (2014). High prevalence of substance use and associated factors among high school adolescents in Woreta Town, Northwest Ethiopia: a multi-domain factor analysis. BMC public health, 14(1), 1186. https://doi.org/10.1186/1471-2458-14-1186

The commission, N. P. (2009). Federal Republic of Nigeria Official Gazette-Legal Notice on Publication of 2006 Census Final Result. Abuja: Federal Government Printer.

DESA, U. (2010). United Nations Department of Economic and Social Affairs/Population Division (2009b): World Population Prospects: The 2008 Revision. Retrieved from http://esa.un.org/unpp

DeVore, E. R., \& Ginsburg, K. R. (2005). The protective effects of good parenting on adolescents. Current opinion in pediatrics, 17(4), 460-465. https://doi.org/10.1097/01.mop.0000170514.27649.c9

Dida, N., Kassa, Y., Sirak, T., Zerga, E., \& Dessalegn, T. (2014). Substance use and associated factors among preparatory school students in Bale Zone, Oromia Regional State, Southeast Ethiopia. Harm reduction journal, 11(1), 21. https://doi.org/10.1186/1477-7517-11-21

Dilorio, C., Parsons, M., Lehr, S., Adame, D., \& Carlone, J. (1992). Measurement of safe sex behavior in adolescents and young adults. Nursing research. https://doi.org/10.1097/00006199-199207000-00003

Fanta, M., Lemma, S., Sagaro, G., \& Meskele, M. (2016). Factors associated with Adolescent-parent communication regarding reproductive health issues, among high school and preparatory students in Boditi town, Southern Ethiopia: a cross-sectional study. Patient Intelligence, 8, 57-70. https://doi.org/10.2147/PI.S97838

Farzaneh, R., Lori, A., \& Karima, K. (2008). Advancing research to inform reproductive health policies in the Middle East and North Africa: July.

Guilamo-Ramos, V., \& Bouris, A. (2008). Parent-adolescent communication about sex in Latino families: A guide for practitioners: National Campaign to Prevent Teen and Unplanned Pregnancy.

Guilamo-Ramos, V., Bouris, A., Lee, J., McCarthy, K., Michael, S. L., Pitt-Barnes, S., \& Dittus, P. (2012). Paternal influences on adolescent sexual risk behaviors: A structured literature review. Pediatrics, 130(5), e1313-e1325. https://doi.org/10.1542/peds.2011-2066

Izugbara, C. O. (2008). Home-based sexuality education: Nigerian parents discussing sex with their children. Youth \& Society, 39(4), 575-600. https://doi.org/10.1177/0044118X07302061

Jejeebhoy, S. J. (2006). Sexual and reproductive health of young people: expanding the research and programme agenda. Paper presented at the David and Lucile Packard Foundation's Population Program Review Task Force Meeting. California.

Kim, Y. M., Kols, A., Nyakauru, R., Marangwanda, C., \& Chibatamoto, P. (2001). Promoting sexual responsibility among young people in Zimbabwe. International family planning perspectives, 11-19. https://doi.org/10.2307/2673800 
Kumi-Kyereme, A., Awusabo-Asare, K., Biddlecom, A., \& Tanle, A. (2007). Influence of social connectedness, communication and monitoring on adolescent sexual activity in Ghana. African journal of reproductive health, 11(1), 133. PMID: 20698062. https://doi.org/10.2307/25549736

Kusheta, S., Bancha, B., Habtu, Y., Helamo, D., \& Yohannes, S. (2019). Adolescent-parent communication on sexual and reproductive health issues and its factors among secondary and preparatory school students in Hadiya Zone, Southern Ethiopia: an institution-based cross-sectional study. BMC pediatrics, 19(1), 9. https://doi.org/10.1186/s12887-018-1388-0

Melaku, Y. A., Berhane, Y., Kinsman, J., \& Reda, H. L. (2014). Sexual and reproductive health communication and awareness of contraceptive methods among secondary school female students, northern Ethiopia: a cross-sectional study. BMC Public Health, 14(1), 252. https://doi.org/10.1186/1471-2458-14-252

Morris, J. L., \& Rushwan, H. (2015). Adolescent sexual and reproductive health: The global challenges. International Journal of Gynecology \& Obstetrics, 131, S40-S42. https://doi.org/10.1016/j.ijgo.2015.02.006

Motsomi, K., Makanjee, C., Basera, T., \& Nyasulu, P. (2016). Factors affecting effective communication about sexual and reproductive health issues between parents and adolescents in zandspruit informal settlement, Johannesburg, South Africa. The Pan African Medical Journal, 25. https://doi.org/10.11604/pamj.2016.25.120.9208

Mturi, A. J. (2003). Parents' attitudes to adolescent sexual behaviour in Lesotho. African journal of reproductive health, 25-33. https://doi.org/10.2307/3583210

Organization, W. H. (2004). Adolescent pregnancy.

Seme, A., \& Wirtu, D. (2008). Premarital sexual practice among school adolescents in Nekemte Town, East Wollega. Ethiopian Journal of Health Development, 22(2), 167-173. https://doi.org/10.4314/ejhd.v22i2.10067

Shiferaw, K., Getahun, F., \& Asres, G. (2014). Assessment of adolescents' communication on sexual and reproductive health matters with parents and associated factors among secondary and preparatory schools' students in Debremarkos town, North West Ethiopia. Reproductive health, 11(1), 2. https://doi.org/10.1186/1742-4755-11-2

Titiloye, M. A., \& Ajuwon, A. J. (2017). Knowledge and quality of adolescents reproductive health communication between parents and their adolescents children in Ibadan, Nigeria. Journal of public health in Africa, 8(1). https://doi.org/10.4081/jphia.2017.688

Widman, L., Choukas-Bradley, S., Noar, S. M., Nesi, J., \& Garrett, K. (2016). Parent-adolescent sexual communication and adolescent safer sex behavior: A meta-analysis. JAMA pediatrics, 170(1), 52-61. https://doi.org/10.1001/jamapediatrics.2015.2731

Yadeta, T. A., Bedane, H. K., \& Tura, A. K. (2014). Factors affecting parent-adolescent discussion on reproductive health issues in Harar, Eastern Ethiopia: a cross-sectional study. Journal of environmental and public health, 2014. https://doi.org/10.1155/2014/102579

Yesus, D. G., \& Fantahun, M. (2010). Assessing communication on sexual and reproductive health issues among high school students with their parents, Bullen Woreda, Benishangul Gumuz Region, North West Ethiopia. Ethiopian Journal of Health Development, 24(2). https://doi.org/10.4314/ejhd.v24i2.62956

\section{Copyrights}

Copyright for this article is retained by the author(s), with first publication rights granted to the journal.

This is an open-access article distributed under the terms and conditions of the Creative Commons Attribution license (http://creativecommons.org/licenses/by/4.0/). 